be preserved. The fishes collected by the Belgica in the Weddell Sea were all pelagic. One species, a Nematonurus, came from a depth of 2800 metres. In addition to the account of the first deep-sea fish collected within the Antarctic circle, there is an account of a larger collection made in the Magellan Archipelago, accompanied by a bibliography and full account of the fish fauna of that area. The fish are not only described and illustrated with M. Dollo's usual skill and care, but their significance is discussed in the very interesting chapters devoted to their zoo-

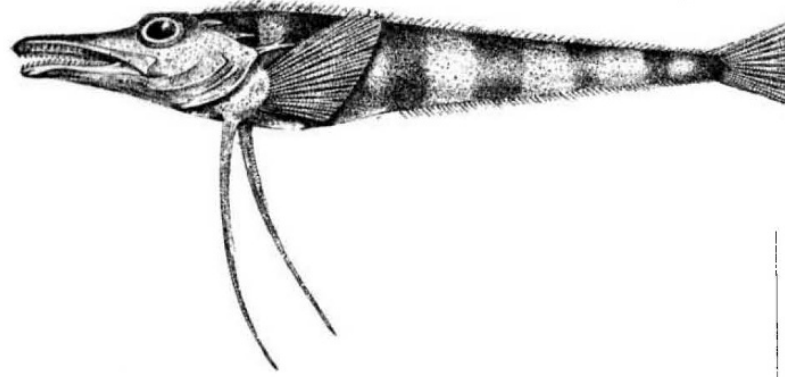

Fig. 3.-Cryodraco, according to Robertson's sketch made on the Erebus.

logical and geographical relations. M. Dollo maintains that the Antarctic fish are of modern development and highly specialised, and are not, as has been thought, a primitive fauna. He discusses the problem of bipolarity, which has commanded wide attention owing to its advocacy by Sir John Murray. M. Dollo maintains that the evidence of the fish gives no support to this theory. Thus he points out that in the Antarctic area the predominant family of fish is that of the Nototheniidæ, whereas in the Arctic Ocean the dominant group is the Cottidæ. In the wide distribution of the Nototheniidæe in the Southern Ocean and the South Pacific M. Dollo sees further support of the existence of the assumed Miocene Antarctic continent, connected with New Zealand, Australia,

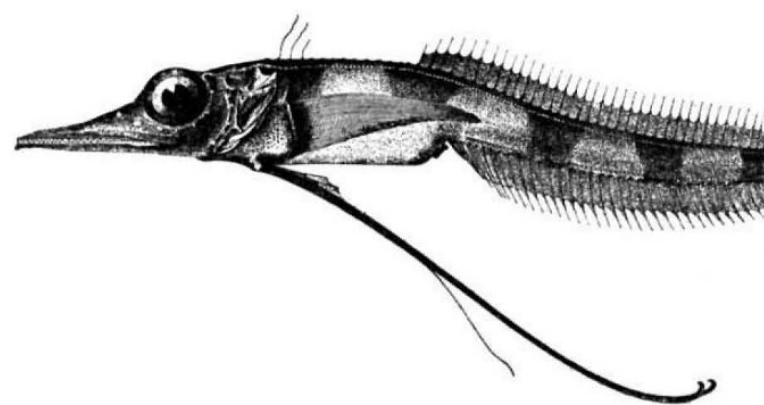

Fig. 4.-Cryodraco, according to Dollo.

and South America, but separated from South Africa; for eleven-twelfths of the Nototheniidæ are littoral species, and, according to Dollo, they can only have spread along the former shores of this sunken land.

J. W. G.

\section{YELLOW JACK.}

THE main facts established regarding yellow fever and mosquitoes can be summed up in a few propositions.

(I) The cause of yellow fever is unknown.

1 Report to the Government of British Honduras upon the Outbreak of Yellow Fever in that Colony in 1905. together with an Account of the Distribution of the Stegomyia fas iata in Belize, and the Measures necessary to stamp out or prevent the Recurrence of Yellow Fever. By Rubert Boyce, M.B., F.R.S. Pp. ix tro4tis Plates. (London: Waterlow and Sons Ltd., rgo6.)

NO. I9I7, VOL. 74]
(2) Yellow fever is transmitted by one particular mosquito, known to science as Stegomyia fasciata, and by no other mosquito or in any other way.

(3) In order to transmit the infection, the Stegomyia must have sucked the blood of a patient during the first three days of the fever, not earlier (during the incubation period), and not later.

(4) The infection is transmitted after an incubation pcriod in the mosquito of not less than twelve days, and the mosquito may still be infectious fifty-seven days after its first infection.

It is a peculiar fact that although there are many species of Stegomyia, so far as is known it is only $S$. fasciata that is capable of transmitting the disease. If we may accept this as established, it points to a peculiar relationship between the mosquito and yellow fever which is not exactly paralleled by the case of any other disease-transmitting agent, be it mosquito, fly, or tick.

In the case of malaria, filariasis, and trypanosomiasis there is not this absolutely limited correlation between the disease and the agent that transmits. Malaria we know is transmitted only by mosquitoes of the subfamily Anophelina of the Culicidæ. This subfamily is divided into a number of genera, and not only do different species of the same genus, e.g. Myzomyia culicifacies and Myzomyia funesta, transmit malaria, but also species pertaining to different genera, e.g. Pyretophorus costalis and Anopheles maculipennis, or, if we do not accept these as different genera, and classify them all as belonging to a single genus, Anopheles, still we have the fact of transmission by different species. In filariasis the correlation between Filaria and the mosquito is still less definite; thus not only various species of Culex, but various species of Anopheles all permit of the development of the microfilariæ (filarial embryos) in their tissues. (It may be well to say in passing that the proof that mosquitoes actually do transmit Filaria is still wanting.)

Our knowledge of the correlation of trypanosomes and flies, especially species of Glossina, Tabanus, and Stomoxys, is still incomplete. Ngana, the tsetse-fly disease of Africa, is transmitted by species of Glossina, but not by Stomoxys or Tabanus. The trypanosome of sleeping sickness is transmitted by Gl. palpalis mainly, but also by other species; but it is not yet known which exactly these are.

Again, in the transmission of various species of Piroplasma by ticks, various genera and species of ticks suffice to transmit the same species of Piroplasma.

As to the transmission of Spirochretes by ticks, our knowledge is at present incomplete, and it would be especially interesting to discover if the relationship were as strict as it appears to be in yellow fever, for Spirochætes (invisible) have been suggested by Schaudinn as the possible cause of yellow fever.

The fact, then, that yellow fever appears to be transmitted by only one genus of mosquitoes, and only one species in that genus, points to some very peculiar relationship, and would suggest an organism as the cause, of a different kind from any of those we have mentioned, and, indeed, this is no doubt the case, as, if it had not been so, the cause would have been already discovered.

Yellow fever, then, is transmitted by a particular and practically world-wide mosquito, Stegomyia fasciata. The fact still requires emphasis that mosquitoes only transmit disease from the sick person to the healthy after certain changes have proceeded in the tissues of the mosquitoes, and that mosquitoes 
do not get malaria, yellow fever, \&c., from the water of pools or marshes.

The author in this report emphasises the necessity for the knowledge of these facts, for, as he points out, it is useless to expect an intelligent carrying-out of prophylactic measures by those ignorant of the present state of our knowledge, or by those who have

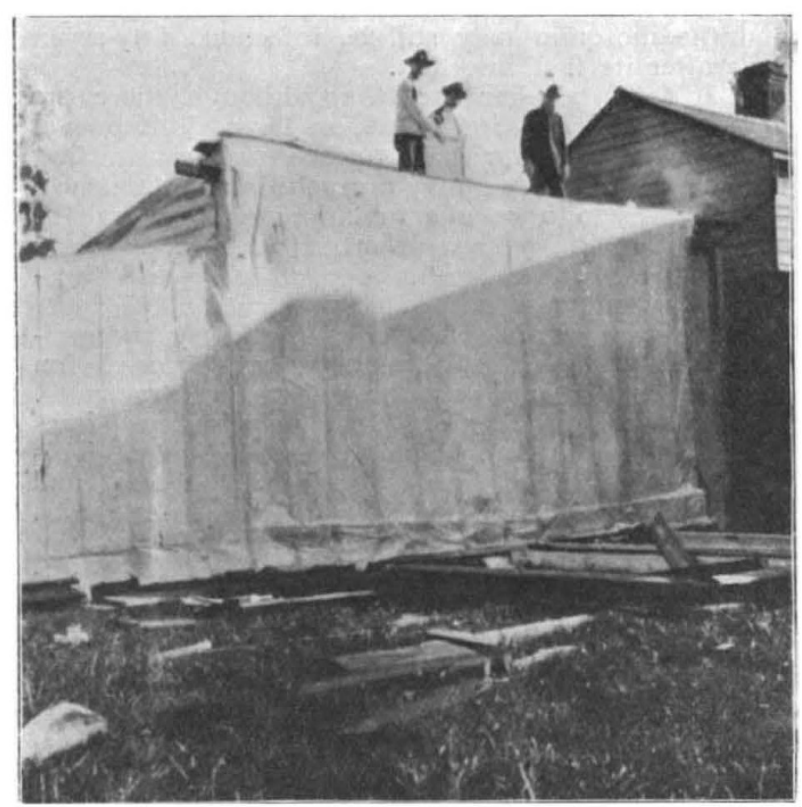

Fig. 1.- Operations in yellow fever prophylaxis at New Orleans. An outhouse completely closed with paper.

a "conscientious belief" that malaria is due to marshes and yellow fever to digging the soil.

The Stegomyia fasciata is essentially a domestic mosquito, i.e. it frequents houses, it breeds in domestic utensils, pots, cisterns, tubs, tins, calabashes, boats, flower-pots, \&c., in fact, in any collection of water about a house.

The destruction of larvæ is, therefore, a comparatively simple matter, and if the water were emptied out, thousands of potential mosquitoes would be at once destroyed. Where it is impossible to empty any collection of water, then the simple device of covering the receptacle with suitable gauze has the same effect. So that the destruction of larvæ of Stegomyia can readily be effected if only people will or can be compelled to do it!

We may express some doubt, however, as to what would happen supposing Stegomyia suddenly by some governor's edict found all their breeding tubs emptied of water or covered over. Would they be content to die, or would they now breed in ditches, canals, slowly-flowing streams, \&c., as Anophelinæ do? We think they would choose the latter course, and this point is not solely of academical interest, for the most vigorous campaign against tubs and cisterns might have been carried out, and yet the Stegomyia might now be enforced to breed in drains, canals, \&c., and if these existed in the midst of the No. I9I7, vOL. 74] town it is conceivable that the condition of things might be no better than before. For the doing away with canals, \&c., implies drainage and re-levelling, and is a far more expensive matter than mosquitodestroying in back-yards. But no considerations of this kind should restrain us from doing our utmost absolutely to free a town of its tub-bred larvæ, and that this is possible is shown by experience at Havana and New Orleans.

Not only must the larvæ be proceeded against, but also all adult mosquitoes, and that this is not the impossible task it might at first sight appear has also been shown by the Americans.

By very simple means, by pasting up a house with sheets of paper, and by the use of a suitable fumigating mixture (camphor and carbolic acid), not only rooms, but outhouses and sheds can be expeditiously and completely freed from mosquitoes.

By these means the epidemic of yellow fever in New Orleans of 1905 was rapidly brought to an end. The history of the epidemic shows what can be done by systematised effort supported by the intelligent cooperation of the whole of a city.

The present very able and comprehensive report sets out at length the conditions prevailing in British Honduras, showing how in Relize, the capital, and other towns all those conditions exist which in the light of our present knowledge should not exist. Stegomyia fasciata exists in profusion, and breeds freely, and so far without hindrance, in water vats, tanks, wells, barrels, tins, and a multitude of other receptacles.

In considering the origin of the outbreak of the disease in British Honduras, the author adopts the view that the disease was imported, and does not discuss another possibility. It is well known, however, that among the native population in yellowfever areas the children suffer from extremely mild attacks of fever, and, indeed, many of these cases are not recognised as such. By this means an endemic supply of yellow fever may always exist, and it may be only at some years' interval that the disease breaks out again in epidemic form.

Apart from this, however, the outbreak of the epidemic is minutely traced, and the difficulty of

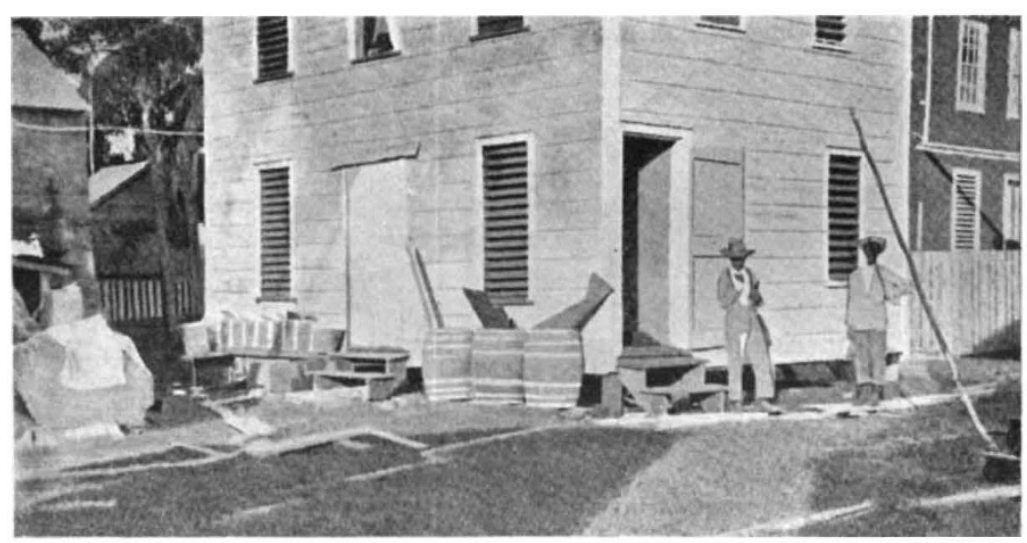

FIG. 2.- House in Belize with waterlogged yard. Numerous water receptacles consisting of barrels and kerosene tins.

detection of early cases, and the resulting fatality under such conditions, emphasised.

The necessity for efficient sanitary survey, especially in the matter of breeding-places, is pointed out.

Finally, we have a complete account of the influence on shipping and disturbance of trade of such an out- 
break, and a full discussion of quarantine regulations of various authorities.

For the administrator and sanitarian in yellowfever zones the report is indispensable. For permission to reproduce the above two plates we are indebted to the courtesy of the Colonial Office.

\section{J. W. W. Stephens.}

\section{SCIENTIFIC WORK OF THE SURVEY OF} INDIA. ${ }^{1}$

$\mathrm{F}$ any apology were needed for the maintenance of the scientific work of the Indian survey it will be found in No. 9 of the series of professional papers of that department, which has been especially prepared for the use of the Survey Committee of Igo5 by Lieut.-Colonel S. G. Burrard, R.E., F.R.S., the Superintendent of Trigonometrical Surveys in India. That committee was appointed for the purpose of examining into the existing system of the Indian Survey Department with the view of rendering it more efficient as a topographical institution, having regard to the increasing demand for more accurate military mapping in India, and the necessity for more perfect revision of those maps which are gradually falling out of date with the advance of public works developments. India is an unscientific country. The scientific members of the Anglo-Indian community would hardly fill a first-class carriage on any railway line, and they exist only as paid servants of the Government, living in constant fear of " reduction" when any financial crisis occurs. They have to justify their existence from time to time, and Colonel Burrard is to be congratulated on the very effective justification which he has given to the public for the maintenance of the scientific branches of his own department. It is all the more valuable for the reasons that the booklet which contains his opinions is written in clear and simple language, intelligible even to the most unscientific reader, and that it appeals directly to a far wider circle of men of science than can be found in any one department. The various sections of the scientific work which Colonel Burrard superintends are principal triangulation, levelling, astronomical, pendulum, magnetic and tidal observations, and solar photography. He deals with them all in turn concisely, showing their relative interdependence and their practical utility.

No distinction is drawn by Colonel Burrard between scientific and practical work. He maintains rightly that their relations are constant. "The primary object of a national survey is the making of maps, and all operations are subordinated to that end. It is for topographical purposes that a national survey measures its allotted portion of the earth's surface. If, however, these measurements be combined wit': astronomical determinations, the size and shape of the earth can be deduced, and a knowledge of this size and shape is essential to astronomers, geographers, geologists and meteorologists, all of whom look to surveys for information." Here, then, is the principle of geodetic triangulation enunciated, and the wholesome doctrine recalled to mind that it is the measurement of " areas," and not " arcs," which will be found most useful for the geodesist as for the practical topographer. The connection between

1 Survey of India, Professional Papers, Serial No. 9, rgo5:-An Account of the Scientific Work of the Survey of India, and a Comparison of its Progress with that of Foreign Surveys prepared for use of the Survey Committee, 1905. A pamphlet by Lieut.-Col. S. G. Burrard, R.E., F.R.S (Calcutta: Office of the Superintendent of Government Printing, 1906.)
Price $1 s .6 d$.

$$
\text { NO. I } 917 \text {, VOL. 74] }
$$

the principal triangulation and secondary methods is well illustrated, and incidentally we are shown the relative degrees of accuracy of the triangulations of different countries. Taking the ratio between precision and length of the triangulation of Great Britain as a unit, we find that ratio to be 0.6 in Russia and 0.7 in India, the only two countries which can claim a superior degree of accuracy; while in France and Prussia it rises to 2.5 and 2.6 respectively, and we are told that South Africa and the United States are equal in precision to France and Prussia. This is something of a surprise, for we were always under the impression that the triangulations of these two last countries was of a very high degree of accuracy as compared with that of older systems.

Colonel Burrard proceeds to show that we have by no means arrived at an ideally accurate framework for the basis of our mapping even yet. Accurate as the process of measurement may be, inaccuracies in the data for reducing observations introduce very considerable and very practical errors. The deflection of the plumb line, the deformation of the earth's figure (which has upset the original calculations of the earth's size, giving it a diameter which is two miles too short), and other physical causes of initial error have this effect, amongst others, viz., that we are rooo feet too far north with our position of Peshawar in northern India, and two and threequarter miles too far east with our position of the Salween River in Burma. This is of little consequence until we come to an international junction with other surveys. It has already had a certain effect in the junction of the geographical surveys of Afghanistan and Russia, which (after making due allowance for these errors) was fairly satisfactory. When, however, a connection between the principal triangulations of these two countries is effected, it may become necessary to revise our Indian data; but, as Colonel Burrard wisely points out, unless we are to continue systematically to combine with other countries (notably South Africa and America) in the elucidation of those scientific problems which form the basis of the world's mapping, we shall never reach the possibility of a final revision which will place our international boundary pillars in the same terms as regards their position on the earth's surface.

No practical surveyor will quarrel with Colonel Burrard's conclusions, or be disposed to criticise his plea for extending the principal triangulation of India far enough to cover the Indian borderlands, where it is of almost paramount importance that we should possess a substantially accurate basis for topography. After all, this preliminary work of the most scientific class only adds ro per cent. to the final cost of the survey.

The interdependence of astronomical, pendulum (for investigating the eccentricities of the force of gravity), and levelling operations is duly emphasised, and in connection with the latter some interesting details are given regarding the probable heights of the highest peaks in the Himalayas. These details have already been referred to in the pages of NATURE. Investigations into magnetic phenomena and solar physics speak for themselves. They cost little, and add greatly to the sum of our scientific knowledge of the data surrounding certain most obscure and elusive natural forces.

As a unit in the series of professional papers of the Indian survey, this is perhaps the most important that has yet appeared, and it is one which appeals to a world-wide community of practical surveyors. 